\title{
The church of cryopreservation
}

A lthough death and taxes are said to be the only two certainties in life, a small but vocal community takes issue with the inclusion of the former. There is, they say, the alternative of cryonics, in which a legally dead person is preserved at $-196^{\circ} \mathrm{C}$ in hopes that he will ultimately be revived and rejuvenated, once a cure for his ailment is found.

And it's entirely consistent with the basic tenets of medicine, providers argue.

"Although it seems like an unusual and radical idea to many people, I think in the very truest sense of the term, this is conservative medicine," says Max More, CEO of the Alcor Life Extension Foundation, a cryonics provider based in Scottsdale, Arizona. "This is literally conserving a patient rather than giving up on them by today's standards of medicine. It's true a doctor can't do anything more for these people, but that doesn't mean the future cannot."

Those interested in cryonics tend be optimistic, hopeful about technological developments and dissatisfied with an ordinary life span, says Ben Best, president of the Cryonics Institute, a cryonics service provider based in a regional township in Michigan. There is a "very high representation of computer nerds in cryonics," adds Best, a former computer programmer. "People in computer technology are very familiar with having problems they can deal with and fix and for technology to be able to solve various problems."

The cryonics movement was established by Robert Ettinger, author of The Prospect of Immortality (Doubleday: Garden City NY; 1964) and founder of the Cryonics Institute. He was cryopreserved in 2011 and is now stored in liquid nitrogen in Michigan.

Some scientists concur with Ettinger's assertion that cryonics does not violate any known laws of physics, but others wrestle with the odds.

"The probabilities are so low," says Peter Mazur, a cryobiologist and research professor at the Department of Biochemistry and Cellular and Molecular Biology at the University of Tennessee in Knoxville. "You can't prove maybe that they're zero — that is to say

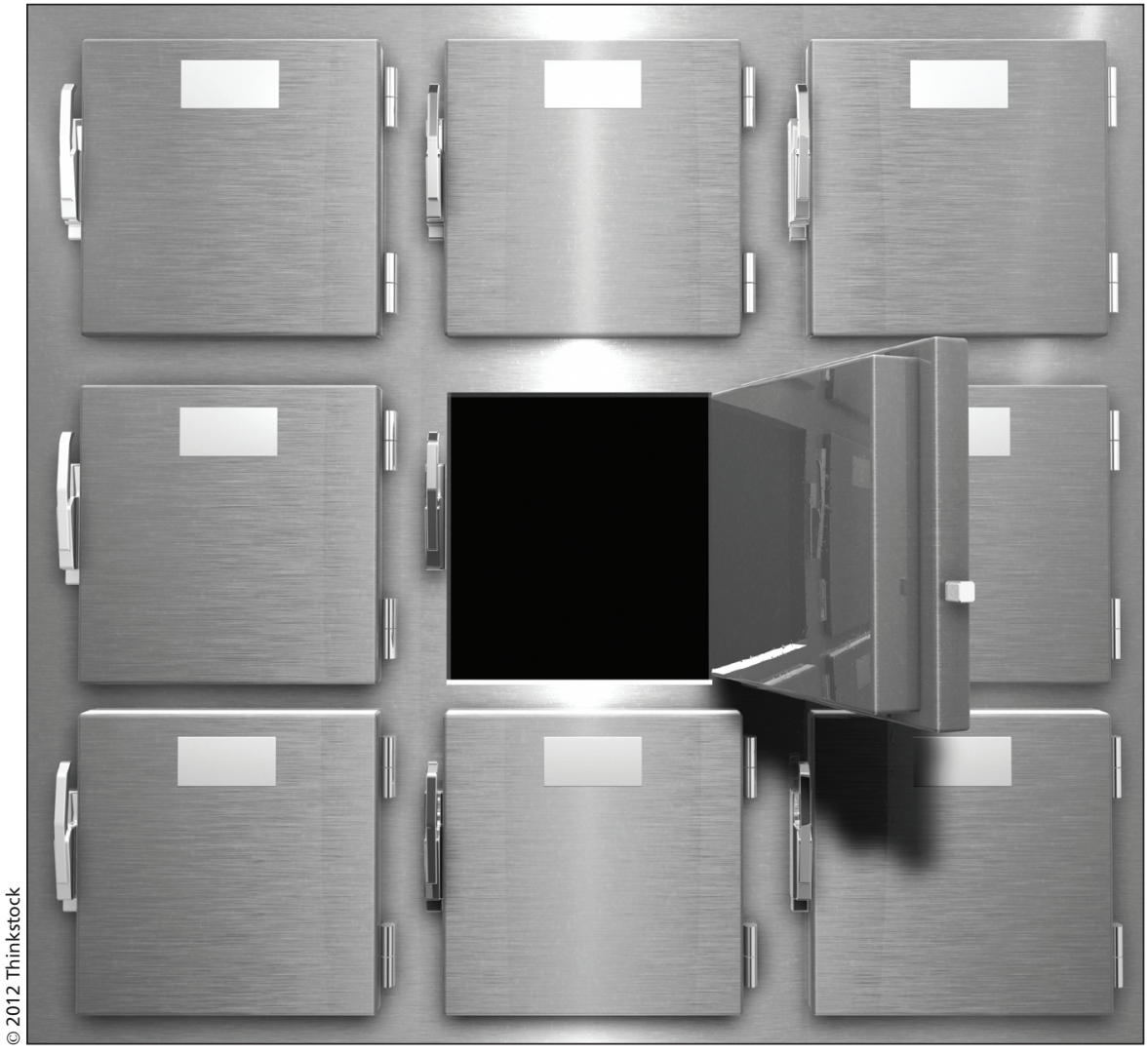

A minuscule chance is better than none, cryonics enthusiasts say.

that it can't be done - but you can I think demonstrate that the probability of its being done is so extremely low that effectively it is zero."

But "just because there's nothing to rule out that it can be done doesn't mean that it can be done," Mazur adds. "If something becomes so improbable to do, I think you have to think of it in those terms and not just whether it's an absolute yes it can be done or no it can't be done."

Others are even more skeptical.

"It's just one of these diversions that raises false expectations," says John Baust, lead professor and director of the Institute for Biomedical Technology at Binghamton University, State University of New York. "I think individuals who are contemplating participating in this practice need to recognize that they're really buying a lottery ticket and the odds are not particularly good."

But a minuscule chance is better than none, enthusiasts say.

"Nobody has come up with a better idea yet, so therefore myself, as well as some others, believe that cryonics is simply the second worst thing that can happen," says Christine Gaspar, a registered nurse and president of the Cryonics Society of Canada. "You're going to die. You're going to stop breathing. Whether you be buried or cremated or cryopreserved, it's going to happen. There's nothing we can do about this now, but I know that if I'm cremated or buried, even if technology vastly increased, I'm never coming back."

No legitimate cryonics provider would tell an interested party that cryopreservation definitely works or is even likely to work, as that would be fraudulent, Best says. And as the company's FAQ page attests, there are many variables that affect the chance of success, such as how quickly after cardiac arrest a corpse is vitrified and the precise state the corpse was in when death was pronounced (http://cryonics.org/prod.html).

Beyond that lies the thorny issue of whether returning to life would even be desirable in a future that could feature fallout from significant climate change, 
nuclear war, natural resource depletion, overpopulation or a host of other human miscues. Such factors could also affect whether rejuvenation will be possible, says Philip Rhoades, executive officer of the Cryonics Association of Australasia, an organization based in Australia that advocates for cryonics and assists people in making cryopreservation arrangements with providers in other countries. "Cryonics isn't a religion where you just sign up and once you've signed up then you don't have to worry about anything, you're saved-forever-sort-of-thing."

Enthusiasts are mystified that only a small segment of the general population has investigated the cryonic option. "I don't know why there are far more people who don't sign up for cryonics arrangements," says More. "It's true that what we do is unorthodox and different, at least in 2012. But there are so many bizarre ideas out there which have no evidence to support them and get many, many people fascinated and adherence. Yet we only have less than 1000 members after 40 years."

Keegan Macintosh, a third-year law student at the University of British Columbia, director of the Cryonics Society of Canada and head of the UBC Life Extension Club, surmises that many people simply accept the inevitability of death. "People tend in my experience to kind of rely on this naturalistic facility that because people have always gotten older and died, therefore they should get older and die as a result of simply living longer."

Others suspect that religious considerations come into play or that there isn't much interest in cryonics because there's a widespread perception that it just doesn't work.

Lack of mainstream interest is most likely simply due to the latter perception that cryonics isn't valid science, says Charles Grodzicki, a 73year-old in West Vancouver, British Columbia, who argues interest would be elevated if a celebrity selected the cryonic option. But thus far, few have, although Ted Williams, an all-star outfielder for the Boston Red Sox, was cryopreserved in 2002. - Michael Monette, Ottawa, Ont. 